\title{
EXPANSÃO DA CANA-DE-AÇÚCAR E OS IMPACTOS SOBRE CULTURAS AGROALIMENTARES NO ESTADO DE SÃO PAULO
}

\author{
OLIVEIRA, Letícia Cristina de ${ }^{1}$ \\ TURCI, Aline Aparecida da Silva ${ }^{2}$ \\ CAPITANI, Daniel Henrique Dario ${ }^{3}$
}

\begin{abstract}
RESUMO: A rápida expansão da cana-de-açúcar no Brasil, a partir de 2000, tem levantado diferentes questões de caráter ambientais, sociais e econômico. Dentre esses, podem-se citar aspectos como da segurança alimentar, envolvendo questões acerca do uso da terra destinada à atividade agrícola. Neste sentido, com o foco no estado de São Paulo, principal produtor nacional, esta pesquisa teve como objetivo avaliar alguns possíveis impactos econômicos dessa expansão sobre culturas agroalimentares em diferentes mesorregiões, entre 2000 a 2014. Em geral, as principais constatações são que a expansão da cana-de-açúcar, que se deu tanto em áreas tradicionais, como nas de expansão, não reduziu a oferta nacional e estadual de alimentos e, portanto, não afetando a segurança alimentar do país. Por outro lado, apesar da diminuição da área plantada ou destinada às culturas agroalimentares, o avanço da cana-de-açúcar contribuiu para um incremento na geração de valor da produção agrícola em escala regional, permitindo uma maior dinamização econômica e melhorando os indicadores econômicos locais, sobretudo nas áreas de expansão.
\end{abstract}

Palavras-chave: Cana-de-açúcar. Sustentabilidade. Segurança alimentar. Expansão agrícola.

SUMMARY: The increasing of sugarcane production in Brazil, especially from 2000, has evidenced different questions about social, economic and environmental issues. Among them, it is important to mention food security concerns, which comprises questions related to the land use for agricultural purposes. Thus, focusing the state of São Paulo, the greater sugarcane producer in Brazil, this research proposes to investigate the connections of sugarcane expansion in this State over food commodities output in different mesoregions. The period considered consists from 2000 to 2014. Using data from de Annual Agricultural Municipality Research, the main findings pointed that the expansion has spread over both traditional as new areas. However, evidences suggest no significant reduction in the regional food supply and, therefore, there were no effects on the food security of the country. Despite that, the decreasing in the planted area of local food commodities, the advance of sugarcane has contributed to a significant increasing in the value of the agricultural production, allowing a greater economic dynamic and improving the regional socioeconomic indicators, especially in the areas of expansion.

Keywords: Sugarcane. Sustainability. Agricultural expansion. Food security.

\section{INTRODUÇÃO}

O setor sucroenergético brasileiro apresentou uma considerável expansão a partir do início da década de 2000. A área plantada com cana-de-açúcar no país passou de cerca de 5 milhões de hectares de área plantada no ano 2000, para mais de 10 milhões de hectares em 2016 (UNICA, 2017). A expansão se deu, sobretudo, em áreas onde predominavam, até então, o cultivo de grãos e outras culturas alimentares, como feijão, mandioca e laranja, além da pecuária de corte, as quais situadas no oeste e norte paulista, Triângulo Mineiro, Sudoeste de Goiás, Mato Grosso do Sul e Mato Grosso. Tal avanço consolidou a

\footnotetext{
${ }^{1}$ UFV - graduanda em Engenharia Agronômica - FCA/UNICAMP - bacharel em Gestão do Agronegócio

${ }^{2}$ Bacharel em Administração - FCA/UNICAMP

${ }^{3}$ Professor Doutor na Faculdade de Ciências Aplicadas da Unicamp (FCA/UNICAMP)
} 
posição estratégica do Brasil na produção de açúcar e biocombustíveis e permitiu uma nova dinamização da distribuição agrícola em diferentes regiões onde a cana-de-açúcar passou a se destacar (IBGE, 2017).

Com intuito de aprofundar o entendimento do papel dessa commodity no cenário agrícola nacional, sobretudo após sua rápida expansão, diversos estudos têm analisado aspectos inerentes às mudanças no uso da terra que tal fenômeno tem causado, especialmente os ambientais e socioeconômicos, buscando agregar conhecimentos e meios de produção menos invasivos ao meio ambiente e que, ao mesmo tempo, não influenciem negativamente na produção agroalimentar básica (CHAGAS et al., 2008; GALDOS et al.., 2010; LEAL et al. 2013). Dentre os pontos destacados, têm-se o levantamento de questões sobre a segurança alimentar no contexto global, como, por exemplo, elencando-se a expansão da cana-de-açúcar sobre áreas antes destinadas à produção de grãos estaria levando a algum impacto negativo sobre a oferta global de alimentos e, neste caso, podendo incorrer em aumentos nos preços das commodities agrícolas e podendo levar a uma possível insegurança alimentar.

Neste sentido, a presente pesquisa se propõe a avaliar os condicionantes da expansão da cana-deaçúcar e seus impactos sobre a produção de culturas agroalimentares. Especificamente, a análise é centrada no estado de São Paulo, principal produtor nacional e que apresentou significativo incremento nas áreas plantadas com cana-de-açúcar. Objetiva-se, assim, analisar questões conjunturais regionais que possam ter sido modificadas a partir desta expansão, avaliando-se como tais mudanças no uso da terra afetaram alguns indicadores da produção canavieira e das demais culturas, como impactos na produtividade agrícola e na geração de valor de produção.

Uma análise conjuntural acerca da expansão da cana-de-açúcar se justifica, sobretudo, no sentido da análise da sustentabilidade socioeconômica nas áreas em que esta cultura agrícola e sua agroindústria assumiram uma posição estratégica nos últimos anos. A análise de indicadores socioeconômicos destas regiões permite uma maior elucidação de fatores relacionados às vantagens ou desvantagens econômicas de uma mudança no cenário local e, assim, munir instrumentos para discussão dos seus reais impactos sobre as economias locais. Por fim, a análise no estado de São Paulo se justifica em razão deste ser o maior produtor canavieiro do Brasil e, possibilitar, também, a análise tanto a partir das áreas tradicionalmente produtoras, quanto das áreas de expansão, onde ocorreram maiores modificações na substituição de lavouras.

Deste modo, o estudo é dividido em duas frentes. Primeiramente com uma revisão de literatura crítica sobre a questão dos impactos da expansão da cana-de-açúcar em relação aos aspectos da sustentabilidade, com maior foco na questão da produção de alimentos. Posteriormente, segue-se com a tabulação e discussão de dados secundários referentes a dados socioeconômicos regionais e relacionados à produção agrícola nas mesorregiões paulistas.

\section{REFERENCIAL TEÓRICO}

\subsection{Aspectos da sustentabilidade e suas interfaces no setor sucroenergético}

No âmbito do comércio, embora alguns estudos tenham demonstrado ${ }^{4}$ que a cadeia têm suprido adequadamente questões sob o escopo ambiental, barreiras comerciais, sobretudo ao etanol, são aplicadas em diferentes mercados sob alegações diversas de cunho ambiental e socioeconômico, como, por exemplo, aspectos da mudança no uso da terra, desmatamento, poluição do ar e água, degradação do solo, concorrência com alimentos, condições insatisfatórias de saúde e trabalho no campo. Estes pontos têm sido amplamente discutidos, justificando a necessidade de estudos que avaliem o ciclo de vida da

${ }^{4}$ Entre estes, pode-se citar Galdos et al. (2010), Leal et al. (2013), Cavalett et al. (2013).

Nucleus,v.16,n.1,abr.2019 
produção de cana-de-açúcar e seus derivados.

A cultura da cana-de-açúcar em si já possui características que cooperam com a esfera ambiental do desenvolvimento sustentável, pois é uma planta que realiza o sequestro de carbono da atmosfera através do seu processo de fotossíntese. Segundo Alexander (1973, apud CHOHFI; DUPAS; LORA, 2004, p. 3), "a biomassa da cana-de-açúcar absorve o dióxido de carbono através da fotossíntese e o armazena na sua composição na forma de carbono. O seu potencial fotossintético ultrapassa o da grande maioria das plantas na flora brasileira".

Além disso, a cana-de-açúcar tem papel relevante na matriz energética brasileira, principalmente pela produção de etanol hidratado e anidro, e também na geração de energia a partir da queima do bagaço e palha, a qual é utilizada pela própria usina no seu processo produtivo, ou exportada à rede de distribuição (BENEDUZZI; MASHIBA; RAMOS, 2005; COSTA; DUARTE, 2010).

A cogeração de energia elétrica através da biomassa da cana-de-açúcar é uma das matrizes energéticas que se enquadram no MDL presente no Protocolo de Kyoto. Tal processo, ao ser implementado, além de cooperar com a redução dos Gases de Efeito Estufa (GEE), permite a obtenção de certificação internacional para comercialização no mercado de crédito de carbono, tornando-se mais uma alternativa de negócios para o setor sucroalcooleiro, e, ao mesmo tempo contribuindo para amenizar os impactos ambientais (SANTANA; ROCHA, 2015).

Estudos aplicados também ao bagaço e à palha da cana-de-açúcar têm mostrado resultados positivos com a produção de etanol de $2^{a}$ geração (DIAS et al., 2013; LEAL et al., 2013; NAKANISHI, 2018). Esse tipo de tecnologia se torna mais uma fonte de rentabilidade, pois além de não afetar a produção de açúcar e etanol ( $1^{\mathrm{a}}$ geração), pode ser produzida durante o ano todo, até mesmo no período de entressafra da cana, e tem o mesmo potencial energético do etanol de $1^{a}$ geração, o que contribui para incrementar as receitas do setor.

As políticas públicas adotadas pelo governo também vieram como elemento incentivador do desenvolvimento sustentável. Na esfera ambiental, a primeira preocupação foi com as mudanças climáticas, sendo criada, em 1992, a Convenção-Quadro, o primeiro grande reconhecimento político e público referente ao assunto, resultado de um longo processo iniciado em 1988 com a formulação do Painel Intergovernamental sobre Mudança do Clima (IPCC), com a finalidade de estudar fenômenos ligados às mudanças climáticas (PORTAL BRASIL, 2014).

No que se refere às políticas públicas do governo brasileiro para incrementar práticas sustentáveis na agricultura, Rampazo et al. (2016) descrevem que os recentes relatórios do Painel Intergovernamental sobre Mudança do Clima (IPCC), em 2014, e as decisões da $21^{\text {a }}$ Conferência das Partes (COP-21), em 2015, contribuíram para a existência de discussões referentes à redução dos GEE. Neste enfoque, tem ganho destaque, a temática da análise da Avaliação de Ciclo de Vida (ACV). Cavalett et al. (2013) explicam que a ACV se trata de uma ferramenta para avaliar os impactos ambientais comparativos das diferentes opções de combustíveis para transporte e biocombustíveis. Ao analisarem o ciclo de vida da produção do etanol de cana-de-açúcar brasileiro, os autores afirmam que se trata de um combustível avançado, isto é, cujo ciclo colabora em mais larga escala para redução da emissão de GEE e uso de fontes fósseis na produção e transportes.

Em vista do panorama que se fundamenta nos debates acerca da sustentabilidade existente no sistema produtivo da cana-de-açúcar, é oportuno levantar também, a questão do carbono no solo. A crescente demanda mundial de bioetanol exige uma avaliação detalhada da sustentabilidade dos biocombustíveis. De acordo com Galdos et al. (2010), a má qualidade do solo deixados no campo podem ser provenientes da queima de biomassa e das baixas quantidades de resíduos remanescentes, ou seja, pode levar a perdas de solo por escoamento superficial se houver uma mistura entre a baixa cobertura 
cobertura do solo com os eventos de precipitação erosiva.

Recentemente, por conta da rápida expansão das áreas cultivadas por cana-de-açúcar, a discussão sobre recurso hídrico também se torna relevante no cenário mundial. O cultivo da cana, em sua maior parte, é alimentado pela chuva, porém com as ampliações territoriais dessa cultura, os recursos hídricos têm sido empregados através de sistemas de irrigação em áreas com déficit, o que vem gerando preocupações (HERNANDES et al., 2018). Entretanto, o maior problema se concentra nas usinas, principalmente na produção de etanol (SMEETS et al., 2006).

Como forma de orientar a expansão do cultivo da cana no Brasil, o governo federal lança, em 2009, a política pública de Zoneamento Agroecológico da Cana-de-açúcar (ZAECana) que propõe avaliar os condicionantes das áreas mais propícias para o plantio, levando em consideração clima, solo, irrigação, biomas, declividade do terreno, dentre outras características (BRASIL, 2009).

Para expandir o desenvolvimento sustentável do setor sucroenergético brasileiro, o governo do estado de São Paulo, as Secretarias de Estado do Meio Ambiente e de Agricultura e Abastecimento, a UNICA e a Organização de Plantadores de Cana da Região Centro-Sul do Brasil (ORPLANA) firmam, em junho de 2007, o Protocolo Agroambiental do Setor Sucroalcooleiro do Estado. O projeto incentiva a adoção de boas práticas no setor, desenvolvendo ações que estimulem a sustentabilidade da cadeia produtiva do açúcar, etanol e bioenergia. E também visa reconhecer e premiar as boas práticas ambientais através de certificação anual de conformidade para as empresas que trabalharem dentro das normas estabelecidas, gerando, assim, reconhecimento dos seus esforços e influenciando diretamente e positivamente na imagem da empresa frente ao mercado interno e externo (SÃO PAULO, 2017).

Ainda, na esfera social, as principais discussões são acerca de melhores condições e segurança para os trabalhadores do campo. No passado recente, a colheita da cana-de-açúcar era majoritariamente feita manualmente e, frequentemente, os trabalhadores rurais vivenciavam condições insalubres, com carga horária elevada, trabalho informal (sem registro em carteira), baixa remuneração, falta de equipamentos de segurança, expostos a períodos prolongados diante das condições climáticas e falta de estrutura adequada para acomodação e locomoção.

Neste sentido, em 2007, a Secretaria de Estado da Saúde de São Paulo, através do Centro de Vigilância Sanitária (CVS) - órgão da Coordenadoria de Controle de Doenças (CCD), cria o Programa Paulista de Vigilância à Saúde do Trabalhador do Setor Canavieiro, cujo objetivo era minimizar, controlar e eliminar os riscos à saúde dos trabalhadores do setor por meio da fiscalização das lavouras, usinas, destilarias e habitações coletivas (CVDSP, 2007).

Em 2009, o governo federal e entidades de trabalhadores e de empresários do setor sucroenergético firmam também o Compromisso Nacional para Aperfeiçoar as Condições de Trabalho na Cana-de-Açúcar com o intuito de melhorar as condições de vida e trabalho no cultivo manual da cana. Este projeto foi considerado um marco histórico na valorização e disseminação das melhores práticas trabalhistas na lavoura, além de, fomentar a reinserção ocupacional dos trabalhadores desempregados pelo avanço da mecanização da colheita (DUARTE; MALHEIROS, 2015).

Diversos trabalhos recentes apontam melhorias nas condições trabalhistas na cultura canavieira brasileira, como ressaltam Capitani et al. (2015), podendo-se observar evolução nos indicadores trabalhistas, como maior grau de formalização do trabalho na agricultura, melhores remunerações, criação de postos de trabalho na área de expansão, melhorias dos indicadores de escolaridade, idade e gênero, e redução no número de autos de infração ocasionados de irregularidades trabalhistas no campo, resultados das políticas públicas implementadas tanto localmente, como nacionalmente. No entanto, apesar da evidente melhora, os autores alertam que algumas irregularidades ainda são existentes, ressaltando a necessidade de continuação das frentes de fiscalização, bem como de buscar aprimoramentos 
aprimoramentos contínuos das políticas públicas existentes e que levem em consideração as particularidades de cada região.

\subsection{Setor Sucroenergético e a Produção de Alimentos no Brasil}

Diante de todo o cenário apresentado, é possível perceber a relevância do setor sucroenergético, no Brasil e no mundo, e sua rápida expansão para a produção de biocombustíveis, sendo uma alternativa de substituição de combustíveis fósseis, atendendo, em partes, aos preceitos da sustentabilidade.

Ao relevar-se, porém, as perspectivas da continuidade do crescimento populacional no mundo nas próximas décadas, indagações acerca da sustentabilidade desse sistema e os possíveis impactos na produção, acessibilidade e preços dos alimentos para a garantia da segurança alimentar da população mundial vêm sendo discutidas (ONU, 2017).

Em temática similar, diversos autores têm proposto analisar a questão dos impactos de biocombustíveis sobre alimentos, sobretudo para o mercado norte-americano, em virtude da recente escalada na oferta de etanol de milho. Alguns destes trabalhos se utilizaram de modelos de análise de equilíbrio parcial para avaliar a mudança direta e indireta no uso da terra para diferentes culturas.

Para o caso brasileiro, podem-se citar, em estudos que utilizaram modelos de equilíbrio geral ou parcial, os trabalhos de como Nassar et a. (2011), Chen Khanna (2013) e Nuñez et al. (2013). Outros, utilizaram-se de análises autorregressivas para avaliar a questão dos preços e volatilidades das commodities agrícolas envolvidas na produção de biocombustíveis e alimentos, em um mesmo mercado. Citando alguns estudos que propuseram identificar tal associação no Brasil, têm-se Balcombe e Rapsomanikis (2008), Capitani (2014), Kristoufek et al. (2015), Bini et al. (2015).

Em geral, considerando a literatura internacional, tais estudos apontam que, salvas análises isoladas, ou para alguns períodos específicos, não se pode afirmar que houve relação direta na expansão da produção de biocombustíveis sobre a oferta global e preços internacionais das commodities agroalimentares. Para o caso brasileiro, nenhum desses estudos conseguiram demonstrar a associação entre a expansão da cana-de-açúcar e impactos negativos na oferta de alimentos.

Especificando os estudos que adentraram nesta temática em específico ao Brasil, tratando a questão do etanol de cana-de-açúcar, Capitani (2014) objetivou investigar os impactos da expansão da produção de cana-de-açúcar e etanol no Brasil nos mercados domésticos de commodities agrícolas através da análise de preços e no relacionamento de longo prazo entre combustíveis e preços agrícolas. A análise expôs que não há um efeito significativo entre o aumento da produção de cana-de-açúcar e do etanol nos preços dos principais produtos consumidos no mercado interno. Resultados similares foram obtidos por Bini et al. (2015), porém limitando a análise a culturas mais centrais, as quais soja e milho, e incluindo ao modelo os preços da cana, petróleo e taxa de câmbio, além de variáveis de preços internacionais (EUA) de milho e etanol.

Chagas, Toneto-Junior e Azzoni (2008) analisaram estatisticamente a relação entre a expansão da área plantada de cana-de-açúcar, preço da terra e custos dos alimentos. Os autores apresentam que a principal preocupação quanto a esse tema é com relação à disponibilidade de terras agricultáveis para a expansão da cultura, e revelam que é um mito que a expansão da cana se fará em terras empregadas por produção de alimentos, e que consequentemente pressionariam os preços destes, gerando um impacto negativo sobre a distribuição de renda. Isto se dá, sobretudo, pela extensão do território brasileiro e a quantidade disponível de terras prontas e aptas para a agricultura e que são subutilizadas.

Já Goes e Marra (2008) analisaram a expansão da cana-de-açúcar e seu embate com a produção de alimentos por meio da sustentabilidade. Eles apontam que a expansão da cultura da cana no Brasil e a 
produção de biocombustíveis não impactam negativamente os preços e a produção de alimentos, bem como não geram aumento do desmatamento na Amazônia. Neste sentido, os autores apontam que além da área total plantada de cana-de-açúcar ser menos que $2 \%$ da área nacional, a expansão se dá no centro-sul do país, ficando, portanto até 2 mil quilômetros de distância da Floresta Amazônica. Além disso, os autores consideram que o país é referência em pesquisa de melhoramento da cultura, garantindo uma maior produtividade, sem necessariamente aumentar a área de plantio.

Para Perosa (2014) os impactos da expansão canavieira na segurança alimentar devem ser examinados em diferentes níveis: global, nacional e regional. $\mathrm{Na}$ avaliação global, a produção de biocombustíveis não apresentou influência na oferta e aumento dos preços das culturas agroalimentares. Já na esfera nacional, mesmo havendo retração da área de cultivo de diversos produtos agrícolas, a expansão da cana não vem gerando grandes impactos na produtividade dos principais produtos alimentícios. Porém na visão regional, regiões cuja agricultura é marcada por monoculturas, o impacto da substituição é menor do que em regiões com predominância da agricultura familiar de subsistência, pois a mudança do uso da terra poderia gerar impactos sobre o acesso aos alimentos por parte destes produtores, criando, portanto riscos localizados à segurança alimentar.

Silva, Oliveira e Lima (2010), por outro lado, alertam que a expansão da cana-de-açúcar no Brasil trouxe um conflito entre a produção de alimentos e produção de matéria-prima para biocombustíveis. Mas analisando sobre a ótica do estado de Goiás, onde aplicaram suas pesquisas, notou-se que apesar da expansão da cana, não houve impacto sobre a produção e oferta de alimento no estado. Porém, observouse que o estado, um dos principais produtores de grãos no país, reduziu sua participação e geração de estoque para culturas consideradas essenciais para a garantia da segurança alimentar, como arroz e feijão.

Portanto, pode-se aferir que os distintos pontos de vista são relevantes para a criação de uma visão crítica sobre o assunto, devendo cada aspecto ser avaliado de forma individual, com a finalidade de gerar análise mais detalhada e imparcial sobre $\mathrm{o}$ assunto.

\section{METODOLOGIA E DADOS}

A estruturação metodológica da presente pesquisa é composta, primeiramente, de uma análise descritiva da literatura empírica acerca das questões relacionadas à expansão da produção de biocombustíveis e suas distintas formas de investigação acerca de possíveis paradoxos em relação à oferta de alimentos. A pesquisa descritiva permite realizar levantamentos relativos às características de uma população, eventos, economia global ou mesmo um mercado específico, possibilitando estabelecer relações de dependência entre as variáveis, sendo possível, assim, generalizar os resultados encontrados (MARTINS, 2004; GIL, 2010). De acordo com Andrade (2007), os fatos devem ser observados, registrados, analisados, classificados e interpretados, sem a interferência do pesquisador, ou seja, sem haver tratamento dos dados ou métodos que procurem averiguar ou testar a informação.

Segundo Prodanov e Freitas (2013), as pesquisas descritivas são a maioria entre as desenvolvidas nas ciências humanas e sociais, como as pesquisas de opinião, mercadológicas, levantamentos socioeconômicos e psicossociais, como, por exemplo, as que têm por objetivo estudar as características de um grupo. Além disso, este tipo de pesquisa utiliza técnicas padronizadas de coleta de dados, como observação sistemática, questionários, entre outros.

A revisão de literatura, por sua vez, utiliza-se de uma pesquisa exploratória, a qual visa proporcionar maior familiaridade com o problema, objetivando elucidá-lo e auxiliar na construção da hipótese. De acordo com Prodanov e Freitas (2013), "a pesquisa exploratória auxilia na investigação do assunto central, possibilitando uma melhor definição e delineamento do tema, objetivos e hipóteses". 
Segundo Gil (2010), assume, em geral, as formas de pesquisas bibliográficas e estudos de caso, permitindo o estudo do tema sob vertentes e aspectos distintos, tal como o próprio levantamento bibliográfico, entrevistas com agentes que possuam experiências práticas com o problema de pesquisa e, análises de exemplos e casos gerais que estimulem sua compreensão. Na avaliação da forma de abordagem do problema, pode-se classificar o estudo como: quantitativa e qualitativa, em que o primeiro lida com fatos e o segundo com fenômenos (KAUARK; MANHÃES; MEDEIROS, 2010).

Assim sendo, com o desenvolvimento desta pesquisa, deseja-se constatar se o avanço da cana em São Paulo, em detrimento às outras atividades agrícolas, trouxe ganhos econômicos em escala regional, associando o objeto à problemática da questão da segurança alimentar.

Desse modo, o estudo realiza um levantamento de informações e dados sobre a produção agrícola do estado de São Paulo, bem como de suas mesorregiões, utilizando como base as informações contidas nos relatórios anuais da Produção Agrícola Municipal (PAM), do Instituto Brasileiro de Geografia e Estatística (IBGE), para o período de 2000 a 2014, período que compreende as fases iniciais, de consolidação e estabilização do avanço da cana-de-açúcar no estado.

De forma a dinamizar a discussão, os dados da PAM/IBGE foram consolidados e analisados de forma mais acurada nas mesorregiões onde a cultura canavieira apresentou alguma relevância sobre suas áreas agricultáveis totais, em pelo menos um dos anos do período amostral. Ainda, a análise relativa a outras culturas alimentares se restringiu à comparação com atividades agrícolas, em razão da base de dados não apresentar dados da pecuária. Neste sentido, foram categorizadas as principais culturas agrícolas que tiveram alguma relevância em cada uma das mesorregiões, para se comparar sua evolução em comparação com a da cana-de-açúcar ao longo do período de análise.

\section{RESULTADO E DISCUSSÃO}

\subsection{Setor Sucroenergético Brasileiro}

Em conjunto com os dados previamente apresentados demonstra-se adiante o comportamento da expansão do setor sucroenergético paulista, a fim de pautar como de fato deu-se essa expansão e seus impactos, tanto fisicamente quanto economicamente no período compreendido entre 2000 a 2014 nas mesorregiões que compõem o estado de São Paulo.

Em geral, de acordo com IBGE (2017), enquanto a área destinada aos cultivos das lavouras temporárias e permanentes no Brasil cresceu em torno de 55\%, entre 2000 a 2014, no estado de São Paulo, o uso da terra para a agricultura, excetuando-se a cana-de-açúcar, apresentou uma expansão mais moderada. No entanto, quando se analisa individualmente o cultivo da cana-de-açúcar no estado, o crescimento da lavoura é de aproximadamente $100 \%$, evidenciando a importância do avanço desta cultura em substituição a outras.

Comparativamente, observa-se que, no ano de 2000, a cana-de-açúcar foi responsável por 9\% dentre as áreas com cultivo no Brasil, enquanto em 2014 representava em torno de 14\%, ou seja, um incremento de aproximadamente 67\%. Com variação similar neste mesmo período, a cana-de-açúcar avançou de $43 \%$ para $67 \%$ da área total plantada no estado de São Paulo, evidenciando, assim, sua expansão. Na figura 1, é possível observara distribuição territorial da área ocupada por cana-de-açúcar, especificando-se as mesorregiões que mais se destacaram no período.

Comparando-se os cenários para os anos de 2000 (pré-expansão) e 2014, observa-se que a expansão da cana-de-açúcar no estado de São Paulo se deu tanto em áreas tradicionalmente produtoras, como as mesorregiões de Ribeirão Preto, São José do Rio Preto, Bauru, Araraquara e Piracicaba, como em áreas anteriormente tradicionais no cultivo de outras lavouras ou na atividade pecuária, como as 
as regiões de Araçatuba, Presidente Prudente, Assis e Campinas.

Figura 1 - Área plantada das lavouras temporárias de cana-de-açúcar nas mesorregiões do estado de São Paulo, ano 2000 e ano 2014, em hectares.

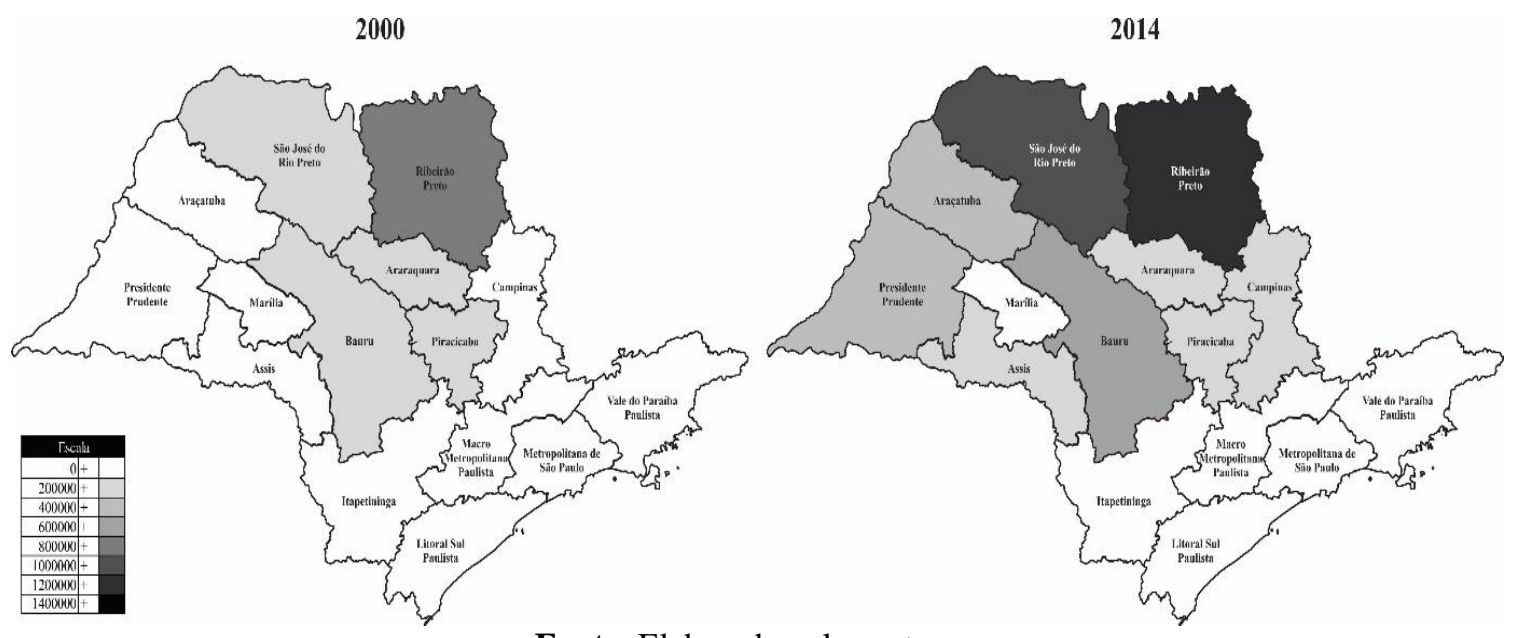

Fonte: Elaborado pelos autores.

Pode-se verificar detalhadamente também, por meio da tabela 4, como se deu esse crescimento, avaliando-se as vertentes da área plantada, quantidade produzida e valor da produção.

Tabela 4 - Dados da expansão das lavouras temporárias de cana-de-açúcar no Brasil, no estado de São Paulo e em suas mesorregiões, no período de 2000-2014

\begin{tabular}{ccccccccccc}
\hline & Brasil & SP & $\begin{array}{c}\text { S. J. Rio } \\
\text { Preto }\end{array}$ & $\begin{array}{c}\text { Rib. } \\
\text { Preto }\end{array}$ & $\begin{array}{c}\text { Pres. } \\
\text { Prudente }\end{array}$ & Araçatuba & Bauru & Assis & Araraquara & Outras \\
\hline \hline $\begin{array}{c}\Delta \text { Área } \\
\text { Plantada }\end{array}$ & 5.574 & 3.082 & 799 & 521 & 474 & 372 & 322 & 176 & 161 & 256 \\
$\begin{array}{c}\Delta \\
\text { Quantidade } \\
\text { Produzida }\end{array}$ & 409.987 & 212.292 & 57.822 & 37.226 & 31.222 & 22.279 & 23.615 & 12.955 & 11.980 & 15.195 \\
$\begin{array}{c}\Delta \text { Valor da } \\
\text { Produção } \\
\text { \% do Valor } \\
\text { da }\end{array}$ & 35.476 & 18.045 & 3.655 & 4.471 & 1.904 & 1.517 & 1.723 & 1.344 & 1.416 & 2.014 \\
Produçãó & 0,92 & 15,45 & 31,94 & 14,48 & 36,52 & 32,11 & 8,47 & 8,4 & 6,28 & 98,32 \\
\hline
\end{tabular}

Fonte: Elaborado a partir de dados da PAM/IBGE (2017).

a: Crescimento absoluto da Área Plantada no período de 2000 a 2014, em milhares de hectares.

b: Crescimento absoluto da Quantidade Produzida no período de 2000 a 2014, em milhares de toneladas.

c: Crescimento do Valor da Produção no período de 2000 a 2014, em milhões de reais.

d: Proporção do Valor da Produção da cana em relação ao total da agricultura. Razão média do período de 2000 a 2014.

Tomando como base a variável Área Plantada, nota-se que a mesorregião de Ribeirão Preto é vista como referência na produção de cana-de-açúcar no estado de São Paulo, sendo a maior produtora em termos absolutos e com expressivo avanço na produção no período. No entanto, o aumento mais substancial se deu na mesorregião de São José do Rio Preto, apresentando uma expansão de aproximadamente 800 mil hectares, tornando-a na segunda maior mesorregião produtora de cana-deaçúcar no estado de São Paulo.

A expansão na área plantada acompanha a taxa de crescimento na produção, uma vez que não há grandes variações de produtividade de uma área a outra. Neste sentido, reforça-se o maior ganho de 
produção nas regiões de São José do Rio Preto e Ribeirão Preto, respectivamente, embora a segunda ainda se mantenha como principal área de produção do estado. Outro destaque se dá para Presidente Prudente, região que não apresentava produção expressiva de cana no início do século, e que apresenta a terceira maior expansão dentre todas. Ainda, importante salientar que as regiões de Araçatuba e Outras (somatória das demais) apresentaram a pior razão entre crescimento da produção em relação ao crescimento da área plantada, ou seja, indicando menor produtividade média no período.

Em relação ao valor da produção, dos $\mathrm{R} \$ 18$ bilhões adicionados pela cultura canavieira no estado de São Paulo, a região de Ribeirão Preto foi quem mais contribuiu, com cerca de R \$ 4,5 bilhões, mesmo apresentando crescimento menor na área cultivada que São José do Rio Preto, a qual adicionou aproximadamente $\mathrm{R} \$ 3,6$ bilhões. Para as demais regiões, o valor acumulado pela área expandida de canade-açúcar foi sempre superior a $\mathrm{R} \$ 1$ bilhão, reforçando a importância dessa cultura nas economias regionais.

Para termos de classificação da relação ganho de produção e incremento econômico, podem-se elencar duas categorias. Primeiramente as mesorregiões com maior aumento do valor de produção gerado pela cana-de-açúcar. Segundo, as mesorregiões com maior crescimento em percentual produzido pela cana-de-açúcar em relação a agricultura geral durante 2000-2014.

Diante disso, ressalta-se que Ribeirão Preto, com R \$ 4,4 bilhões, São José do Rio Preto, com R\$ 3,6 bilhões e Presidente Prudente, com R \$ 1, 9 bilhões, foram as regiões que mais aumentaram o alor de produção gerado pela cultura canavieira. Já as mesorregiões de Marília, com crescimento de 47,22\% no valor da produção, Presidente Prudente, com 36,52\%, e Araçatuba, com 32,11\%, foram as que apresentaram maior crescimento proporcional gerado pela cana-de-açúcar em relação a outras culturas agrícolas, demonstrando que, embora não sendo as principais áreas, foram as que mais se beneficiaram economicamente da substituição de áreas agrícolas heterogêneas, para uma concentração na cultura da cana-de-açúcar.

Também é possível examinar detalhadamente como se comportou a produção de açúcar, etanol anidro e hidratado entre os anos safra de 2000/2001 a 2013/2014 no Brasil e no estado de São Paulo, além da dinâmica do consumo de etanol anidro combustível e etanol hidratado combustível nos anos de 2013 e 2014, no Brasil e em São Paulo.

Ao longo dos 15 anos-safra avaliados, constata-se um avanço linear da produção de açúcar brasileiro e paulista, de acordo com UNICA (2017). Tal crescimento representou cerca de 21 milhões de toneladas no Brasil, das quais 14 milhões foram produzidas no estado de São Paulo. A média de representatividade do estado, durante o período, girou em torno de $62 \%$ da produção nacional.

Seguindo esta mesma diretriz, a produção brasileira de etanol anidro e hidratado aumentou, respectivamente, em torno de 6 milhões $\mathrm{m}^{3}$ e 10 milhões $\mathrm{m}^{3}$. Em São Paulo, o aumento foi de cerca de 3 milhões $\mathrm{m}^{3}$ e 4 milhões $\mathrm{m}^{3}$, respectivamente, o que equivaleu, em média, a $62 \%$ da produção de etanol anidro e $54 \%$ de etanol hidratado (UNICA, 2017).

Com relação ao consumo de etanol, tomando a média para os anos de 2013 e 2014, São Paulo foi responsável por $25 \%$ da demanda nacional de etanol anidro e $57 \%$ de etanol hidratado (UNICA, 2017). Tais números evidenciam a importância do estado no desempenho do setor, sobretudo quando se analisa o consumo de etanol hidratado, principal substituto à gasolina.

\subsection{Setor Agroalimentar Brasileiro}

No cenário do setor agroalimentar, conforme anteriormente mencionado no estudo, o Brasil é visto em âmbito global como exemplo na produção agrícola. Além disso, São Paulo é uma referência na 
produção de alimentos que compõem a alimentação básica da população do país, tais como arroz, feijão, milho, soja, trigo e mandioca, uma vez que é um importante mercado consumidor, polo agroindustrial e centro de distribuição. Ademais, também há culturas perenes com relevante significância para a economia local e nacional, como é o caso da laranja, eucalipto e café, além dos setores de pecuária bovina de corte e leiteira, suinocultura e avicultura.

Neste sentido, em decorrência da já tradicional produção canavieira e sua forte expansão recente, entende-se a pertinência da avalição dos possíveis impactos gerados sobre a produção das culturas agroalimentares, sobretudo aquelas mais diretamente envolvidas na alimentação humana e de cunho agrícola $^{5}$. Balizando-se o período base de 2000 a 2014, avaliam-se a seguir sete culturas alimentares no estado de São Paulo, de pequena ou maior relevância na produção agrícola regional, as quais arroz, feijão, laranja, mandioca, milho, soja e trig. São avaliadas as variáveis, área plantada, quantidade produzida e valor da produção.

Nas tabelas 5, 6 e 7, adiante, apresentam-se as variações na área plantada, quantidade produzida e valor de produção de cada uma dessas culturas para as mesorregiões em análise, considerando o ano 2000 como base, em relação ao ano de 2014.

Tabela 5 - Variação da área plantada das lavouras temporárias de arroz (em casca) no estado de São Paulo e em suas mesorregiões, 2000-2014, em milhares de hectares.

\begin{tabular}{cccccccc}
\hline & Arroz & Feijão & Laranja & Mandioca & Milho & Soja & Trigo \\
\hline Brasil & -1.357 & -1.040 & -168 & -144 & 3.195 & 16.615 & 1.301 \\
SP & -48 & -119 & -179 & 21 & -305 & 159 & 68 \\
S. J. Rio Preto & -13 & -10 & -91 & 0 & -67 & 1 & - \\
Rib. Preto & -6 & -3 & -45 & 0 & -155 & -144 & - \\
Araçatuba & -2 & -17 & 0 & -1 & -33 & 22 & - \\
Bauru & -4 & -3 & 49 & 1 & -42 & 17 & 4 \\
Araraquara & -3 & 0 & -59 & 0 & -9 & 1 & 0 \\
Piracicaba & -1 & 1 & -35 & 2 & -6 & 1 & 0 \\
Campinas & -4 & -5 & -9 & 4 & -15 & -1 & 0 \\
P. Prudente & -2 & -20 & 0 & 3 & -2 & 27 & - \\
Marília & -1 & -2 & 2 & 7 & 1 & 4 & - \\
Assis & -3 & 4 & 6 & 6 & -24 & 19 & 0 \\
Itapetininga & -5 & -46 & 9 & 0 & 45 & 201 & 61 \\
Macro Metrop. Pta. & -1 & -7 & -3 & 0 & 10 & 10 & 3 \\
Vale do Paraíba & -2 & -7 & -1 & 0 & -7 & 0 & - \\
Litoral Sul & -1 & -1 & 0 & 0 & 0 & - & - \\
RMSP & 0 & -1 & 0 & 0 & -1 & - & - \\
\hline
\end{tabular}

Fonte: Elaborado a partir de dados da PAM/IBGE (2017).

Primeiramente, na tabela 5, observa-se que algumas culturas não sofreram impactos significativos em suas lavouras, como mandioca, soja e trigo. Por outro lado, as culturas que mais perderam área no estado de São Paulo foram o milho, laranja e feijão, com redução de 305 mil hectares, 179 mil hectares e 119 mil hectares respectivamente. Elucidando tais números, a perda de área de um período a outro, se considerada em relação à área total plantada na safra 2013/2014, segundo dados da CONAB (2018) e IBGE (2018), corresponderia a uma queda de, respectivamente, 53,8\%, 35,1\% e 40,6\% da área plantada. No entanto, é necessário ressaltar que nem sempre a perda de área se reflete em perda de produção, uma vez da possibilidade de ocorrer incremento na produtividade. Isto pode ser notado na tabela 6 , para o caso do milho, por exemplo.

5 Excluindo, nesta pesquisa, as atividades pecuárias, uma vez que nem sempre são intensivas de uso de áreas diretamente, sobretudo a avicultura, suinocultura e pecuária bovina de confinamento. 
Tabela 6 - Variação da quantidade produzida das lavouras temporárias de arroz (em casca) no estado de São Paulo e em suas mesorregiões, 2000-2014, em milhares de toneladas.

\begin{tabular}{cccccccc}
\hline & Arroz & Feijão & Laranja & Mandioca & Milho & Soja & Trigo \\
\hline Brasil & 1.041 & 238 & -89.723 & 209 & 47.561 & 53.940 & 4.536 \\
SP & -54 & -44 & -76.693 & 548 & 924 & 519 & 217 \\
S. J. Rio Preto & -19 & -11 & -19.835 & -3 & -186 & 0 & - \\
Rib. Preto & -9 & -2 & -11.883 & 8 & -123 & -338 & - \\
Araçatuba & -3 & -17 & -615 & -30 & -108 & 33 & - \\
Bauru & -4 & 11 & -3.080 & 8 & -68 & 53 & 10 \\
Araraquara & -3 & 0 & -16.251 & 7 & -9 & 3 & - \\
Piracicaba & -2 & 2 & -8.310 & 39 & -28 & 2 & 0 \\
Campinas & -7 & -1 & -12.832 & 78 & -22 & -2 & 0 \\
P. Prudente & -3 & -16 & -78 & 58 & 62 & 47 & - \\
Marília & -1 & -1 & -16 & 197 & 29 & 8 & - \\
Assis & -3 & 14 & -480 & 187 & 609 & 78 & 8 \\
Itapetininga & -6 & -12 & -2.420 & 8 & 694 & 609 & 191 \\
Macro Metrop. Pta. & -1 & -3 & -727 & 5 & 89 & 25 & 8 \\
Vale do Paraíba & 6 & -5 & -130 & -7 & -12 & 0 & - \\
Litoral Sul & 1 & -1 & -1 & -3 & -1 & - & - \\
RMSP & 0 & -1 & -34 & -5 & -2 & - & - \\
\hline
\end{tabular}

Fonte: Elaborado a partir de dados da PAM/IBGE (2017).

Pela tabela 6, é possível apontar algumas considerações. Primeiramente, que a perda na produção de arroz e feijão no estado foi pequena, mostrando que a produtividade atenuou os efeitos da redução de área, sobretudo para o feijão. No entanto, embora essa queda tenha sido pouco significativa, nota-se que se contrapôs ao forte crescimento da produção nacional, principalmente no caso de arroz, que apresentou acréscimos superior a 1 milhão de toneladas.

Em segundo lugar, fenômeno similar ocorreu com a quantidade produzida de soja, trigo e milho. No caso dos dois primeiros, houve crescimento de área, aparentemente acompanhado com crescimento na produção, enquanto para o terceiro, houve redução expressiva de área, mas com crescimento de quase 1 milhão de toneladas. Ainda assim, para essas três culturas graneleiras, o incremento na produção se mostrou bem inferior ao crescimento da produção nacional, embora aparentemente expressando a representatividade tradicional da produção paulista de grãos, isto é, não se pode afirmar que a produção graneleira no estado de São Paulo foi afetada negativamente por falta de área, ou por deficiência na produtividade decorrente do uso da terra de áreas menos férteis.

Em terceiro lugar, observa-se o forte crescimento da produção de mandioca. Enquanto a produção paulista cresceu na magnitude de 548 mil toneladas, a produção nacional (incluindo São Paulo) aumentou na ordem de 209 mil hectares, ou seja, São Paulo foi preponderante para alavancar a produção nacional desta commodity.

Por fim, no sentido inverso, a produção estadual de laranja apresentou expressiva queda, levando também a uma queda na produção nacional. Em termos relativos, a queda na produção, se comparado o ano de 2000 com o ano de 2014, foi de aproximadamente 56\%, mostrando que essa cultura foi afetada fortemente no período em questão. Segundo Olivette et al. (2011) e Baptistella et al. (2012), a principal razão da perda de área da citricultura se dá pelas dificuldades técnicas e econômicas enfrentadas pelo setor na década de 2000, como incidência de pragas, altos custos e baixa rentabilidade que, somados ao fato dessa ser uma cultura permanente, na renovação do pomar, muitos produtores paulistas passaram a optar por substituir a cultura por cana-de-açúcar, ou mesmo eucalipto, dadas as maiores rentabilidades obtidas com essas culturas. 
Muito embora a laranja tenha sofrido um significativo impacto na produção, em termos de valor de produção, o valor gerado por essa cultura variou positivamente no período. Pelo fato de ser uma atividade de alta expressividade no estado, seu saldo foi positivo em mais de R \$ 3 bilhões, o mais expressivo em São Paulo (Tabela 7).

Tabela 7 - Variação do valor da produção das lavouras temporárias de arroz (em casca) no Brasil, no estado de São Paulo e em suas mesorregiões, 2000-2014, em milhões de reais

\begin{tabular}{cccccccc}
\hline & Arroz & Feijão & Laranja & Mandioca & Milho & Soja & Trigo \\
\hline Brasil & 5.779 & 3.515 & 4.273 & 6.970 & 19.962 & 75.731 & 2.698 \\
SP & 15 & 159 & 3.018 & 344 & 881 & 1.365 & 130 \\
S. J. Rio Preto & -5 & -6 & 440 & 11 & 6 & 26 & - \\
Rib. Preto & -2 & 7 & 335 & 8 & 22 & 122 & - \\
Araçatuba & -1 & -10 & 19 & 2 & 3 & 58 & - \\
Bauru & 0 & 39 & 757 & 21 & 24 & 72 & 5 \\
Araraquara & -1 & 0 & 449 & 4 & 11 & 8 & - \\
Piracicaba & 0 & 7 & 119 & 20 & 15 & 7 & 0 \\
Campinas & -2 & 27 & 455 & 43 & 93 & 16 & 0 \\
P. Prudente & -1 & -4 & 1 & 42 & 34 & 62 & - \\
Marília & 0 & 0 & 30 & 62 & 15 & 9 & - \\
Assis & 1 & 28 & 106 & 111 & 236 & 332 & 6 \\
Itapetininga & 0 & 67 & 291 & 6 & 363 & 629 & 114 \\
Macro Metrop. Pta. & 0 & 7 & 16 & 7 & 58 & 24 & 5 \\
Vale do Paraíba & 23 & -2 & 0 & 1 & 1 & 0 & - \\
Litoral Sul & 2 & 0 & 0 & 5 & 0 & - & - \\
RMSP & 0 & 0 & 0 & 1 & 0 & - & - \\
\hline
\end{tabular}

Fonte: Elaborado a partir de dados da PAM/IBGE (2017).

Outras culturas apresentaram um resultado mais modesto em nível estadual, como o caso do arroz, feijão, mandioca e trigo. Já a soja e milho expressivo crescimento da nacional e apresentaram resultados próximos ou superiores a $\mathrm{R} \$ 1$ bilhão (Tabela 7). Porém, convém ressaltar que tais resultados, se somados, são inferiores a um terço da geração de valor adicionada pela cana-de-açúcar no estado (Tabela 4).

Ainda, se analisados o perfil da nova distribuição da produção agrícola nas mesorregiões do estado de São Paulo, observa-se que a variação na quantidade produzida foi impactante apenas para a citricultura, tendo essa redução ocorrido em todas as áreas onde tal atividade já era estabelecida, indicando que se deu tanto nas áreas onde a cana-de-açúcar já predominava, quanto naqueles em que sua expansão foi mais significativa. Para as demais culturas, observa-se uma redução ainda que relevante para o milho em São José do Rio Preto, Ribeirão Preto e Araçatuba, e para a soja a soja em Ribeirão Preto. No entanto, deve-se ressaltar que nessas três regiões, se somado todo o déficit de produção mencionado, o saldo negativo para a produção graneleira chega a 755 mil toneladas para uma área perdida de 329 mil hectares, enquanto a agregação de produção e área por parte da atividade canavieira chegou a, respectivamente, cerca de 117 milhões de toneladas e 1,7 milhão de hectares.

Em outras palavras, o fato da produção agrícola, à exceção da laranja ${ }^{6}$, não ter se retraído, concomitante a uma expansão significativa da cana-de-açúcar em muitas das mesorregiões paulistas, leva ao entendimento que o crescimento da produção canavieira se deu independentemente das outras culturas estabelecidas, permitindo uma agregação no valor de produção regional superior ao de todas as outras

${ }^{6}$ E para algumas regiões na produção de milho e soja, embora em magnitudes reduzidas.

Nucleus,v.16,n.1,abr.2019 
culturas somadas, muito embora as demais culturas sequer tenham apresentado redução absoluta em seus valores de produção.

Na tabela 8, pode-se ver a ilustração resumida da produção agregada das culturas graneleiras e mandioca, mais a citricultura e cana-de-açúcar, considerando a diferença na área plantada, quantidade produzida e valor de produção para todas as mesorregiões paulista. Em suma, a perda de área das demais culturas agrícolas no estado de São Paulo em análise equivaleram a 22,5\% do avanço total da área da cana-de-açúcar, sugerindo que esta cultura cresceu em outras áreas, sobretudo terras antes utilizadas para a pecuária intensiva ou outras atividades fim. Excluindo a laranja, as demais atividades evoluíram em termos de produção, embora em magnitudes inferiores à média nacional, sobretudo em razão da forte expansão da soja e milho no Centro-Oeste.

Tabela 8 - Variação na área plantada, produção e valor bruto de produção de grãos e mandioca, laranja e cana-de-açúcar no estado de São Paulo entre 2000 e 2014.

\begin{tabular}{|c|c|c|c|c|c|c|c|c|c|c|c|}
\hline & & Brasil & SP & $\begin{array}{c}\text { S. J. } \\
\text { Rio } \\
\text { Preto }\end{array}$ & $\begin{array}{l}\text { Rib. } \\
\text { Preto }\end{array}$ & Araçatuba & Bauru & Araraquara & $\begin{array}{c}\text { Pres. } \\
\text { Prudente }\end{array}$ & Assis & Outras \\
\hline \multirow{3}{*}{$\begin{array}{c}\text { Grãos e } \\
\text { Mandioca }\end{array}$} & $\Delta$ Área $^{a}$ & 18.570 & -224 & -89 & -308 & -31 & -27 & -11 & 6 & 2 & 238 \\
\hline & $\Delta$ Produção $^{\text {b }}$ & 107.525 & 2.110 & -219 & -464 & -125 & 10 & -2 & 148 & 893 & 2.761 \\
\hline & $\Delta$ Valor Prod. ${ }^{\mathrm{c}}$ & 114.655 & 2.894 & 32 & 157 & 52 & 161 & 22 & 133 & 714 & 2.337 \\
\hline \multirow{3}{*}{ Laranja } & $\Delta$ Área $^{a}$ & -168 & -179 & -91 & -45 & 0 & 49 & -59 & 0 & 6 & -31 \\
\hline & $\Delta$ Produção ${ }^{b}$ & -89.723 & -76.693 & -19.835 & -11.883 & -615 & -3.080 & -16.251 & -78 & -480 & -24.950 \\
\hline & $\Delta$ Valor Prod. ${ }^{\mathrm{c}}$ & 4.273 & 3.018 & 440 & 335 & 19 & 757 & 449 & 1 & 106 & 1.017 \\
\hline \multirow{3}{*}{$\begin{array}{l}\text { Cana-de- } \\
\text { açúcar }\end{array}$} & $\Delta$ Área $^{a}$ & 5.574 & 3.082 & 799 & 521 & 372 & 322 & 161 & 474 & 256 & 176 \\
\hline & $\Delta$ Produção ${ }^{b}$ & 409.987 & 212.292 & 57.822 & 37.226 & 22.279 & 23.615 & 11.980 & 31.222 & 15.195 & 12.955 \\
\hline & $\Delta$ Valor Prod. ${ }^{c}$ & 35.476 & 18.045 & 3.655 & 4.471 & 1.517 & 1.723 & 1.416 & 1.904 & 2.014 & 1.344 \\
\hline
\end{tabular}

Fonte: Elaborado a partir de dados da PAM/IBGE (2017).

a: Crescimento absoluto da Área Plantada no período de 2000 a 2014, em milhares de hectares.

b: Crescimento absoluto da Quantidade Produzida no período de 2000 a 2014, em milhares de toneladas.

c: Crescimento do Valor da Produção no período de 2000 a 2014, em milhões de reais.

\section{CONSIDERAÇÕES FINAIS}

Em meio à expansão da cultura de cana-de-açúcar, acarretada pelo crescimento da demanda de etanol, indagações acerca dos impactos gerados por essa conduta vem tomando visibilidade global nos últimos anos. Desta forma, esta referida pesquisa teve o intuito de analisar a expansão da cana-de-açúcar e sua associação com a produção de culturas agroalimentares no estado de São Paulo.

Em termos da produção canavieira, de 2000 a 2014, a área plantada cresceu na magnitude de aproximadamente 5,6 milhões de hectares no território nacional, sendo 3,1 milhões apenas no estado de São Paulo. Em termos de produção, o acréscimo foi de cerca de 410 milhões de toneladas no Brasil e 212 milhões de toneladas em São Paulo, auferindo, respectivamente, ganhos econômicos de R \$ 35 bilhões e $\mathrm{R} \$ 18$ bilhões no valor de sua produção, respectivamente.

Para as culturas agroalimentares analisadas no estado de São Paulo, em termos de área plantada, ocorreu ligeira a moderada redução nas lavouras de arroz (48 mil hectares), feijão (119 mil hectares), laranja (179 mil hectares) e milho (305 mil hectares). Já as demais culturas, mandioca, soja (em grão) e trigo (em grão), obtiveram um crescimento territorial. 
Contudo, pode-se dizer que todas as culturas tiveram aumento na produtividade média no período, suficiente para superarem, na maior parte dos casos, as perdas de produção decorrentes da redução de área plantada. O impacto negativo se manteve sobre a produção arroz e feijão, porém menos expressivo que a perda de área. Já a laranja apresentou uma perda mais acentuada, sobretudo pelas dificuldades que esse setor vivenciou, de incidência de novas pragas, altos custos e baixos preços no mercado internacional. Entretanto, na esfera econômica, todas as culturas mostraram aspectos positivos com relação ao valor da produção, apresentando incrementos na geração de valor, alcançando ganhos de aproximadamente $\mathrm{R} \$ 6$ bilhões para o estado de São Paulo, acompanhando o crescimento da agricultura do país.

Detalhando a análise sob as perspectivas das mesorregiões que mais se destacam, considerando o início e fim do período em análise, pode-se verificar inicialmente que a cana-de-açúcar possui grande relevância na região de Ribeirão Preto, tradicional área produtora, onde possui maior extensão territorial. Porém nota-se que a mesorregião de São José do Rio Preto apresentou um crescimento mais acentuado, corroborando em maior produção, e com os ganhos econômicos substanciais, os mais elevados do estado.

Ambas regiões foram as que apresentaram, também, maiores perdas de áreas destinadas às outras culturas agroalimentares. Porém, a perda de área, e eventualmente de produção, foi significativamente menos que o incremento das lavouras e da oferta de cana-de-açúcar. Ao subtrair as perdas territoriais das culturas agroalimentares analisadas em relação à área de avanço da cana-de-açúcar, nota-se um excedente de 2,7 milhões de hectares de área plantada, onde pode-se questionar se essa expansão se deu em áreas destinadas à pastagem (pecuária extensiva e semi-intensiva), em áreas sem produção prévia, ou em áreas atribuídas a outras culturas agroalimentares de menor importância que as sete analisadas. Ademais, ambas as regiões apresentaram saldos positivos com relação ao valor da produção, assim como outras regiões produtoras no estado.

Neste sentido, paralelo à questão da segurança alimentar, pode-se inferir que a disponibilidade e acessibilidade de tais alimentos não foram afetadas significativamente, uma vez que as culturas agroalimentares em questão alcançaram suas maiores rentabilidades ao longo dos 15 anos.

Desta forma, pode-se inferir que a expansão canavieira no estado de São Paulo trouxe, proporcionalmente, impactos econômicos substancialmente positivos para as economias de suas mesorregiões produtoras, ou seja, a oferta de alimentos não se retraiu de forma significativa, e os ganhos econômicos mais que compensaram tais perdas, possibilitando, inclusive, de financiar a importação de alimentos de outros estados mais eficientes na produção destas culturas. Adiciona-se a isso a dinamização de diferentes indicadores econômicos regionais, como geração de empregos, incrementos na atividade econômica como um todo, entre outros, que são explorados em diferentes estudos apresentados anteriormente.

Neste sentido, uma pesquisa futura complementar, que agregasse parcialmente os resultados desta pesquisa com outras temáticas de estudo referentes às questões socioeconômicas permitiria inserir novos elementos no debate da expansão da produção de biocombustíveis ou biomassa sobre a oferta de alimentos. Ainda, uma exploração mais detalhada de microdados de caráter social e econômicos, com associação à divulgação dos dados do novo censo agropecuário de 2017, contribuiria para expandir o leque de investigação sobre o tema. Ademais, uma pesquisa com maior abrangência, envolvendo todo o território nacional, considerando a expansão da cana-de-açúcar para outros estados, complementaria os resultados do presente estudo. 


\section{REFERÊNCIAS}

BALCOMBE, K. G.; RAPSOMANIKIS, G. Bayesian estimation and selection of nonlinear vector error correction models: the case of the sugar-ethanol-oil nexus in Brazil. American Journal of Agricultural Economics, Oxford, v. 90, n. 3, p. 658-668, 2008.

BENEDENUZZI, A. H.; MASHIBA, M. H. S.; RAMOS, R. A. V. Mecanismos de desenvolvimento limpo no setor sucroalcooleiro. In: XXI Congresso Nacional de Estudantes de Engenharia Mecânica, 2005, Ilha Solteira, Anais[...] Ilha Solteira, 2005, p. 2.

BAPTISTELLA, C. S. L.et al. 2012: ano difícil para a laranja. Análises e Indicadores do Agronegócio, São Paulo, v. 7, n. 12, p. 1-5, dez. 2012.

BINI, D. A; CANEVER, M. D.; DENARDIN, A. A. Correlação e causalidade entre os preços de commodities e energia. Nova Economia, Belo Horizonte, v. 25, n. 1, p. 143-160, 2015.

BRASIL. Decreto No 6.961, de 17 de Setembro de 2009 aprova o zoneamento agroecológico da cana-deaçúcar. Casa Civil: Subchefia para Assuntos Jurídicos, Brasília, 2009.

CAPITANI, D. H. D. Biofuels versus food: How much Brazilian ethanol production can affect domestic food prices? In: AGRICULTURAL AND APPLIED ECONOMICS ASSOCIATION ANNUAL MEETING, 2014, Milwalkee. Anais... Minneapolis: AAEA, 2014, p. 25.

CAPITANI, D. H. D.; GOMES, M. S.; WALTER, A. C. S.; LEAL, M. R. L. V. Condições de trabalho na atividade canavieira brasileira. Revista de Política Agrícola, Brasília, v. 24, n. 2. p. 64-77, 2015.

CAVALETT, O.et al. Comparative LCA of ethanol versus gasoline in Brazil using different LCIA methods. The International Journal of Life Cycle Assessment, Basingstoke, v.18, n. 3, p. 647-658, 2013.

CHAGAS, A. L. S.; TONETO-JÚNIOR, R.; AZZONI, C. R. Teremos que trocar energia por comida? Análise do impacto da expansão da produção de cana-de-açúcar sobre o preço da terra e dos alimentos. Revista EconomiA, Brasília, v. 9, n. 4, p. 39-61, dez. 2008.

CHEN, X.; KHANNA, M. Food vs. fuel: the effect of biofuels policies. American Journal of Agricultural Economics, Oxford, v. 95, n. 2, p. 289-295, 2013.

CHOHFI, F. M.; DUPAS, F. A.; LORA, E. E. S. Balanço, análise de emissão e sequestro de CO2 na geração de eletricidade excedente no setor sucro-alcooleiro. In: Anais do $5^{\circ}$ Encontro de Energia no Meio Rural, 2004, Campinas - SP. Anais... Campinas, p. 8.

COSTA, P. R. DE O.; DUARTE, F. S. A utilização da biomassa da cana-de-açúcar como fonte de energia renovável aplicada no setor sucroalcooleiro. Revista de Administração da Fatea, Lorena, v. 3, n. 3, p. 2107, jan. / dez., 2010.

CENTRO DE VIGILÂNCIA SANITÁRIA COORDENADORIA DE CONTROLE DE DOENÇAS SECRETARIA DE ESTADO DA SAÚDE DE SÃO PAULO (CVD/CCD/SES-SP). Programa paulista de vigilância à saúde do trabalhador do setor canavieiro. Boletim Epidemiológico Paulista, São Paulo, v. 4, n, 45, p. 24-25, 2007.

DIAS, M. O. S.et al. Cogeneration in integrated first and second generation ethanol from sugarcane. Chemical Engineering Research \& Design, Amsterdã, v. 91, p. 1411-1417, 2013

DUARTE, C. G.; MALHEIROS, T. F. Sustentabilidade e políticas públicas para o setor sucroenergético: Uma análise dos temas abordados. GeAS - Revista de Gestão Ambiental e Sustentabilidade, São Paulo, v. 4, n. 3, Set./Dez., 2015 
FOOD AND AGRICULTURE ORGANIZATION OF THE UNITED NATIONS - FAO. Countries by commodity - Ranking. Roma, 2017. Disponível em: < http://www.fao.org/faostat/ >. Acesso em: 20. fev. 2018.

GALDOS, M. V.et al. Net greenhouse gas fluxes in Brazilian ethanol production systems. GCB Bioenergy, Hoboken, v. 2, n. 1, p. 37-44, 2010.

GIL, A. C. Como Elaborar Projetos de Pesquisa. 5. ed. São Paulo: Atlas, 2010.

GOES, T.; MARRA, R. A expansão da cana-de-açúcar e sua sustentabilidade. Brasília: Embrapa. 2008. Disponível em: < https://www.agencia.cnptia.embrapa.br/ >. Acesso em: 02 jun. 2018.

HERNANDES, T. A. D.; SCARPARE, F. V.; SEABRA, J. E. A. Assessment of the Recent Land Use Change Dynamics Related to Sugarcane Expansion and the Associated Effects on Water Resources Availability. Journal of Cleaner Production, Amsterdã, v. 197, p. 1328-1341, 2018.

INSTITUTO BRASILEIRO DE GEOGRAFIA E ESTATÍSTICA - IBGE. Produção Agrícola Municipal. 2017. Disponível em: < https://sidra.ibge.gov.br/pesquisa/pam/ > . Acesso em: 04 jun. 2018.

INTERNATIONAL RENEWABLE ENERGY AGENCY - IRENA. Global overview on renewable energy capacity \& electricity generation. 2017. Disponível em: < http://resourceirena.irena.org/gateway/dashboard/ >. Acesso em: 15 abr. 2017.

KAUARK, F DA S.; MANHÃES, F. C.; MEDEIROS, C. H. Metodologia da Pesquisa: um guia prático. Itabuna: Litterarum, 2010.

KRISTOUFEK, L.; JANDA, K.; ZILBERMAN, D. Co-movements of ethanol related prices: evidence from Brazil and the USA. CAMA Working Papers, Canberra, 2015.

LEAL, M. R. L. V. ; GALDOS, M. V. ; SCARPARE, F. V. ; SEABRA, J. E. A. ; WALTER, A. C. S. ; OLIVEIRA, C. O. Sugarcane straw availability, quality, recovery and energy use: A literature review. Biomass \& Bioenergy, Amsterdã, v. 53, p. 11-19, 2013.

MARTINS, H. H. T. S. Metodologia qualitativa de pesquisa. Educação e Pesquisa, São Paulo, v. 30, n. 2, p. 289-300, 2002.

NAKANISHI, S.C.et al. Comparative material balances and preliminary technical analysis of the pilot scale sugarcane bagasse alkaline pretreatment to $2 \mathrm{G}$ ethanol production. Industrial Crops and Products, Amsterdã, v. 120, p. 187-197, 2018.

NASSAR, A. M.et al. Biofuels and land-use changes: searching for the top model. Interface Focus, Londres, v. 1, n. 2, p. 224-232, 2011.

NOVACANA. As usinas de açúcar e etanol do Brasil. 2017. Disponível em: < https://www.novacana.com/usinas_brasil >. Acesso em: 13 jun. 2018.

NUÑES, H. M.; ÖNAL, H.; KHANNA, M. Agricultural Economics, Hoboken, v. 44, n. 1, p. 487-499, 2013.

OLIVETTE, M. P. A.et al. Evolução e prospecção da agricultura paulista: liberação da área de pastagem para o cultivo da cana-de-açúcar, eucalipto, seringueira e reflexos na pecuária, 1996-2030. Informações Econômicas, São Paulo, v. 41, n. 3, p. 37-67, mar. 2011.

ORGANIZAÇÃO DAS NAÇÕES UNIDAS - ONU. World Population Prospects: The 2017 Revision. New York, 2017. Disponível em: < https://esa.un.org/unpd/wpp/Publications/Files/WPP2017_KeyFindings.pdf >. Acesso em: 19 jun. 2017. 
PEROSA, B. B. Setor sucroalcooleiro Impactos da expansão canavieira. Agroanalysis, São Paulo, p. 2426, Jan. 2014.

PORTAL BRASIL. Painel Intergovernamental sobre Mudança do Clima (IPCC). Brasília, 2010.

PRODANOV, C. C.; FREITAS, E. C. Metodologia do trabalho científico: métodos e técnicas de pesquisa e do trabalho acadêmico. 2. ed. Novo Hamburgo: FEEVALE, 2013.

RAMPAZO, N. A M.; PICOLI, M. C. A.; MIRANDA, C. G. Avaliação da expansão da cana-de-açúcar no estado de São Paulo e a questão da segurança alimentar. In: X Congresso Brasileiro de Planejamento Energético, 2016, Gramado - RS. Anais[...] Rio de Janeiro: SBPE, 2016.

SANTANA, C. A.; ROCHA, S. A. L. Agroindústria canavieira brasileira: Um estudo teórico-empírico sobre o papel dos projetos de redução de gases efeito estufa no contexto da problemática ambiental e sua contribuição para a economia de baixo carbono. In: CONGRESSO NACIONAL DE EXCELÊNCIA EM GESTÃO, 11. 2015, Rio de Janeiro. Anais[...] Rio de Janeiro: FIRJAN, 2015, p. 23.

SILVA, A. V. DA; OLIVEIRA, D. E. C. DE; LIMA, D. A. L. L. Segurança alimentar: estudo sobre a produção de alimentos em Goiás, 1990-2009. In: V Encontro Nacional da Anppas, 2010, Florianópolis SC. Anais[...] Florianópolis: UFSC, 2010, p. 20.

SÃO PAULO (Estado). Secretaria do Meio Ambiente. Etanol Verde. São Paulo, 2017. Disponível em: http://www.ambiente.sp.gov.br/etanolverde/ Acesso em: 10 Mai. 2017.

SMEETS, E.et al. Sustainability of Brazilian bio-ethanol. Utrecht: STROIS. Copernicus Institute / University of Campinas. 2006.

UNIÃO DAS INDÚSTRIAS DE CANA-DE-AÇÚCAR - UNICA. Exportação e Importação. 2017. Disponível em: < http://www.unicadata.com.br >. Acesso em: 22 mai. 2018.

UNIÃO DAS INDÚSTRIAS DE CANA-DE-AÇÚCAR - UNICA. Produção. 2017. Disponível em: < http://www.unicadata.com.br >. Acesso em: 22 mai. 2018. 